\title{
RESISTENCIA: O CAMINHO PARA O ENFRENTAMENTO ÀS DIVERSAS FORMAS DE VIOLÊNCIA QUE IMPACTAM A VIDA DAS MULHERES NEGRAS
}

\section{Resistance: the path to confront the various ways of violence that impact the lives of black women}

Valdenice José Raimundo (UNICAP)

Informações do artigo

Recebido em 18/03/2018

Aceito em 18/04/2018 $10.25247 / 2447-861 X .2018 . n 243 \cdot P 75-90$

\begin{abstract}
Resumo
Este artigo tem como objetivo refletir sobre a resistência das mulheres negras, numa perspectiva de gênero, frente ao racismo e as demais violências a ele associadas. Traz à tona as estratégias que foram e vêm sendo historicamente utilizadas para o enfrentamento às situações impostas às mulheres negras, numa sociedade organizada a partir das hierarquias dos povos que constituíram o Brasil. Resulta de reflexões que foram realizadas para a $16^{a}$ Semana da Mulher da Unicap que aconteceu nos dias 05 a og de março de 2018. A reflexão procede ainda de uma caminhada orientada pela vivência, pela observação e pelas leituras bibliográficas que levam em conta as experiências concretas das mulheres negras brasileiras. É válido salientar que essas leituras se inserem numa perspectiva que dialoga com a realidade dessas mulheres e não escamoteiam os impactos da desigualdade racial em suas vidas. É uma leitura que considera que o caminho trilhado até aqui resulta em conquistas políticas, legais e de fortalecimento. Este artigo se somará as reflexões teóricas existentes, potencializando o debate que recusa todas as formas de opressão, exploração e discriminação.
\end{abstract}

Palavras-Chave: Gênero. Racismo. Violência. Resistência.

\section{Abstract}

This article aims to cause a reflection on the resistance of black women, from a gender perspective, before racism and other violence associated with it. It brings to the surface the strategies that have been and are being historically used to confront the situations imposed on black women in a society organized from the hierarchies of people who constituted Brazil. It is the result of reflections that were elaborated for the $16^{\text {th }}$ Women's Week of Unicap (Catholic University of Pernambuco) held from March o5 to March o9, 2018. The reflection also comes from a journey guided by the experience, observation and bibliographical readings that take into consideration the experiences of Brazilian black women. It is important to mention that these readings are included in a perspective that talks to the reality of these women and does not erase the impacts of racial inequality in their lives. This reading considers that the path taken so far has resulted in political, legal and strengthening achievements. This article will add to the existing theoretical reflections, empowering the debate that rejects all forms of oppression, exploitation and discrimination.

Keywords: Gender. Racism. Violence. Resistance. 


\section{Introdução}

Este artigo insere-se no campo dos estudos sobre a luta histórica das mulheres negras no Brasil. Tem por objetivo construir aproximações teóricas e reflexivas acerca do racismo entendendo-o como uma manifestação da violência na vida dessas mulheres, apontando a resistência enquanto estratégia de enfrentamento às diversas violências resultantes do racismo.

Dessa forma, este estudo orienta-se pelo seguinte pressuposto: o racismo é uma manifestação da violência e sua manutenção é garantida historicamente na realidade brasileira. Assim, ao se observarem as condições de vida e oportunidade das mulheres negras, supõe-se que não se pode deixar de enfrentar teórica e criticamente a questão das diversas formas de violência que as atinge e que estão associadas ao racismo.

Contribuir com os estudos que dão visibilidade às lutas das mulheres negras, enquanto sujeitos políticos, é deixar claro que essas mulheres nunca estiveram à parte da história, nunca reverenciaram submissamente seus algozes e registraram na história seus esforços de busca pela emancipação de toda população negra.

Esses registros históricos, não orientados por uma perspectiva da história escrita pelo branco dominador, mas de uma perspectiva dos que resistem, têm encorajado, direcionado e, sobretudo, despertado outras mulheres a entenderem essas contribuições e continuarem na luta, que teve início no momento que o/a primeiro/a negro/a foi capturado no continente africano e trazido/a em condições subumanas para o Brasil. Concordando com Werneck (2010) os nossos passos de luta e resistência vêm de longe.

A luta tem sido forjada tendo como horizonte a valorização da cultura, da religião, dos nossos corpos, da nossa capacidade intelectual. Para a autora acima mencionada, as mulheres negras desenvolvem suas estratégias cotidianas de luta em condições profundamente desvantajosas em diferentes esferas, o que impõe limites para pensar e organizar estratégias "capazes de recolocar e valorizar nosso papel de agentes importantes na constituição do tecido social e de projetos de transformação" (WERNECK, 2010, p. 8).

Contudo, para além das dificuldades impostas pela "dominação ocidental eurocêntrica ao longo dos séculos de escravidão, expropriação colonial e da modernidade racializada e racista em que vivemos" (WERNECK, 2010, p.4), as mulheres negras vão-se 
constituindo como sujeitos políticos num diálogo atualizado com as demandas advindas da população negra.

\section{A história e as mulheres negras}

A história das mulheres negras brasileiras tem sido baseada na negação da sua história. Isso tem contribuído para que muitas não percebam que as dificuldades pelas quais têm passado, se articulam com a organização racista da sociedade brasileira. A sociedade em seus fundamentos racistas desqualifica tudo o que se associa ao negro e à África. A negação das suas raízes a distância da possibilidade de resistir coletivamente, de questionar as bases políticas, religiosas e culturais que as oprimem.

Para Gonzalez (1982), ao refletir sobre a situação das mulheres negras brasileiras, a história oficial limitou a presença negra à acomodação, à passividade. Uma imagem estereotipada que remete à aceitação passiva dos processos de opressão. A história que foi contada tinha como objetivo a manutenção dessa ideia distorcida de passividade.

Outros elementos foram ocultados. Carneiro (2011) mostra que, desde o período colonial, as mulheres negras foram submetidas à violação dos seus corpos. Para Souza Pessôa "a mulher negra foi vítima dos mais cruéis abusos pelos senhores que se achavam no direito de fazerem uso de seus corpos como bem entendessem" (2017, p. 30).

Nesse contexto, Carneiro (2001) desmistifica a imagem da senhora branca vista como alguém submissa e subalterna ao controle autoritário do marido portador de sentimentos brutalizados. A mulher branca era por excelência tão autoritária e despótica quanto o homem branco. Por outro lado, a negra tinha que submeter-se às determinações do seu "dono" quando solicitada, não existindo a possibilidade de recusa, tendo que estar com ele independente da sua vontade, senão seria submetida a castigos. Para as autoras acima mencionadas, o estupro contra a mulher negra era praticado em larga escala, ficavam sujeitas a doenças venéreas e a gravidez.

A realidade vivenciada pela escrava era bem distante daquela ideia bastante difundida de que esta era tratada como se fosse um membro da família.

[...] à mesa patriarcal da casa grande sentavam-se como se fossem da mesma família numerosos mulatinhos. Crias, malungos, moleques de estimação. Alguns saíam de carro com os senhores acompanhando-os aos passeios como se fossem filhos. Quanto às mães pretas referem as tradições 
o lugar verdadeiramente de honra que ficavam ocupando nos seios da família patriarcal (FREYRE, 1984, p. 352).

A realidade acima descrita se contrapõe à exposta por Giacomini (1988), que mostra os filhos das escravas sendo tirados delas ainda bebês e abandonados na roda dos enjeitados e/ou vendidos.

Ainda de acordo com Carneiro (2001) as condições históricas nas quais surgiu e se expandiu a relação de "coisificação" que foi imposta ao negro no Brasil e, em particular, às mulheres negras, são suficientemente conhecidas. E isso ocorre graças a sua manutenção.

A realidade de parte significativa das mulheres negras guarda semelhança com o período colonial apesar dos séculos de história que nos distanciam. Vejamos: segundo Rufino (1987) na situação de escravizadas as mulheres negras sobreviviam em condições subhumanas. Fora de sua terra de origem, reduzida à condição de escrava, a mulher negra era utilizada para o trabalho doméstico, para a lavoura, as minas e o comércio. Era entendida como propriedade do senhor. Nos dias atuais, o trabalho doméstico, apesar da conquista da PEC das domésticas, a qual modificou a Constituição Federal (1988) ao promover tratamento igualitário, ou seja, acesso aos direitos sociais e trabalhistas como nas demais profissões, muitas mulheres negras e pobres, ainda, trabalham em condições precárias.

Embasadas nas autoras acima, podemos inferir que, na situação de escravizada ou na situação de trabalhadora livre, a mulher negra se encontra entre os grupos sociais mais explorados e, nos dias atuais, sem cobertura das políticas de proteção social.

No período da escravidão, tudo era realizado pelos negros/as, pois, além de ser trabalhadores do campo, foram mecânicos, rachavam lenha, e com a habilidade das suas mãos fabricavam os luxos da vida "civilizada" (BENTO, 1988). Esta realidade ainda é mantida. Quando observamos a realidade das comunidades são na sua maioria, os/as negros/as, que deixam o subúrbio na direção dos centros para realizar toda sorte de serviços, seja no comércio, nas indústrias, fábricas, ou seja, no serviço formal ou informal. No que diz respeito ao trabalho informal, é visível a presença das mulheres negras, pobres e com baixo nível educacional. Segundo Pesquisa Nacional por Amostra de Domicílios Contínua (PNAD Contínua), divulgada pelo Instituto Brasileiro de Geografia e Estatística (IBGE), no terceiro trimestre de 2017, o Brasil tinha 13 milhões de pessoas sem ocupação no terceiro trimestre de 2017. Desse total, 8,3 milhões, ou 63,7\% se declaravam pretos ou pardos. Com isso, a taxa de desocupação dessa parcela da população ficou em 14,6\%, valor superior à apresentada 
entre os trabalhadores brancos $(9,9 \%)$. Outro dado importante é que pretos ou pardos representavam $54,9 \%$ da população brasileira de 14 anos ou mais e eram $53 \%$ dos trabalhadores ocupados do país. Mas, apesar de ser a maioria, a proporção de pretos ou pardos ocupados $(52,3 \%)$ era inferior à da população branca $(56,5 \%)$. Além disso, o rendimento dos trabalhadores pretos e pardos foi de 1.531 reais, enquanto o dos brancos era de 2.757 reais.

Gonzalez (1982) apresenta uma realidade bastante familiar. A autora nos mostra que, mesmo na condição de mucama, ao findar o trabalho na casa grande, a escravizada voltava para a senzala para cuidar dos filhos que Ihe deixaram com vida, prestava assistência ao companheiro que chegava das plantações, engenhos, quase sem vida devido à fome e ao cansaço.

A responsabilidade da mulher no cuidado com os membros da família faz com que aquelas que entram no mercado (formal ou informal) continuem respondendo pelas tarefas de cuidado, pelas tarefas domésticas. Isso faz com que tenham dupla jornada e sobrecarga de trabalho. Cabe, muitas vezes, à mulher negra, depois das atividades que garantam a sobrevivência (espaço da produção) o espaço da reprodução social de suas famílias.

No entanto, apesar das injustiças, da luta para garantir a existência dos seus descendentes imposta por uma história que insiste em negá-las a condição de sujeito histórico, não faltou a essas, criatividade, esperteza, vontade de escrever uma história (que tem escrito), na qual suas posturas e ações questionam as narrativas da história oficial, colocam em xeque os privilégios, de quem, historicamente, tem-se beneficiado de uma história que já não é mais entendida como única.

\section{A resistência das mulheres negras na história}

No que diz respeito à luta pela vida, compreendida na resistência cotidiana:

[...] é a mulher negra anônima, sustentáculo econômico, afetivo e moral de sua família aquela que desempenha o papel mais importante. Exatamente porque com sua força e corajosa capacidade de luta pela sobrevivência, transmite a suas irmãs mais afortunadas, o ímpeto de não nos recusarmos à luta pelo nosso povo. Mas, sobretudo porque, como na dialética do senhor e do escravo de Hegel - apesar da pobreza, da solidão quanto a um companheiro, da aparente submissão, é ela a portadora da chama da libertação, justamente porque não tem nada a perder (GONZALEZ, 1982, p. 104). 
As mulheres negras sempre reagiram à situação de opressão a que foram forçadas, mesmo que a historiografia oficial, aqui entendida como aquela escrita e narrada a partir da perspectiva dos grupos dominantes, negasse ou ocultasse tais fatos. Sempre existiram aqueles (as) que, de acordo com Giacomini (1988), "furando" os véus da ideologia dominante, contribuíram para mudar o curso da História.

A perspectiva que apresenta os escravizados (as) como sendo pacatos, passivos e estáticos é abalada com o surgimento dos quilombos, palavra que vem do quibundo, uma língua do grupo Banto, cujo significado é habitação e se tornou a forma de resistência mais importante e mais temida do período colonial. "A existência de quilombos imprimia tal receio aos brancos que qualquer ajuntamento de escravos fugitivos já era como tal considerado, não importando seu número diminuto" (GOULART apud BERGMANN, 1978, p. 58).

No século XIX, os quilombos surgiram em maior número em províncias como: Pará, Maranhão, Pernambuco, Paraíba, Minas Gerais, Rio de Janeiro, São Paulo e Santa Catarina. De acordo com uma provisão de 1741, é reputado quilombo desde que se achem reunidos cinco escravos. No Maranhão, em 1847, a assembleia provincial votou a lei 236 , classificando como quilombo a reunião de apenas dois escravos. Para Bento (1998), a organização de quilombos surgiu a partir dos movimentos de negros (as) que lutavam contra a escravidão.

O quilombo mais conhecido foi o Quilombo dos Palmares, formado pelos escravos fugidos de Pernambuco, a mais importante das capitanias. Localizava-se na Serra da Barriga, no atual estado de Alagoas e significava um sonho que lá se havia tornado realidade: a vida livre.

De acordo com Arnt e Neto (1995), a vida livre em Palmares, era caracterizada como uma sociedade multirracial e miscigenada de negros, índios e até brancos pobres. Os ritos africanos conviviam com o catolicismo. Além de fabricar armas e ferramentas com a metalurgia trazida da África, os Palmarinos plantavam milho, fumo, batata, mandioca e faziam comércio com os vizinhos. A produção era trocada por munições, armas, sal, tecidos e ferramentas. As terras eram férteis e havia muita madeira, caça e água. Para Bento (1998), a atividade principal em Palmares era a agricultura, num sistema de trabalho coletivo e faziam uso da metalurgia para fabricar utensílios para a agricultura e armas para a guerra, além de objetos artísticos.

O primeiro líder de Palmares foi Gamga-Zumba. Zumbi torna-se líder após sua morte, formando seu próprio exército como forma de reorganizar a comunidade de Palmares e para 
batalhar contra as várias expedições organizadas por ordem do rei de Portugal. Assassinado pelas forças de repressão da coroa Portuguesa em 20 de novembro de 1695, Zumbi foi esfaqueado, degolado, tendo sua cabeça exposta em praça pública ${ }^{1}$

Na luta por liberdade, Zumbi teve a contribuição de Dandara e Aqualtune, mulheres guerreiras que não se dobraram as imposições do sistema escravocrata. Após a destruição desse reduto, Rufino (1987) infere que Dandara preferiu matar-se a voltar para a condição de escrava.

Diante dessas atrocidades apresentadas na história, as mulheres negras não recuaram e não se acovardaram, resistiram na luta por dignidade humana. A história registrou fugas individuais e coletivas, organizaram quilombos (a exemplo do liderado por Tereza de Quariterê) e associações de proteção e ajuda mútua. Quando da impossibilidade de práticas políticas amplas, realizaram ações individuais como o envenenamento do escravizador, assassinando-os em legítima defesa e, mesmo, articulando rebeldias que causavam prejuízos aos escravizadores, como nos mostra o articulista do Jornal $O$ Americano, que se assinava por Philantropo:

Vemos diariamente elles (os escravos) affectando nenhum cuidado, quebrarem-nos os móveis de maior valor, esquecerem-se dos afazeres que Ihes ordenamos e ainda dos mais curtos e insignificantes recados, soffrendo nossos muito, e sendo sempre mal feitos, a ponto de grandemente perdermos em nossos interesses domésticos (O AMERICANO apud GIACOMINI, 1988, p. 63).

No início do século XIX, houve uma série de revoltas de escravos no recôncavo baiano, onde estavam concentrados escravos Sudaneses oriundos da Costa de Mina. Aliaram-se para essa revolta os Haussenses e os Nagôs. A maior dessas revoltas ocorreu em 1835, que se denominou Revolta dos Malês. Destaca-se, nesse momento histórico, Luíza Mahin, africana guerreira, mãe de Luiz Gama, poeta e abolicionista. Pertencia à etnia jeje, sendo transportada para o Brasil, como escrava. Outros se referem a ela como sendo natural da Bahia e tendo nascido livre por volta de 1812. O pai de Luiz Gama era português e vendeu o próprio filho, por dívida, aos 10 anos de idade, a um traficante de escravos, que o levou para Santos. Sua casa tornou-se quartel general das principais revoltas negras que ocorreram em Salvador em meados do século XIX. Luiza Mahin conseguiu escapar da violenta repressão

\footnotetext{
${ }^{1}$ Atual Praça do Carmo, na Dantas Barreto - Recife.
} 
desencadeada pelo Governo da Província e partiu para o Rio de Janeiro, onde também parece ter participado de outras rebeliões negras, sendo por isso presa e, possivelmente, deportada para a África.

Luiz Gama escreveu sobre sua mãe: sou filho natural de uma negra africana, livre da nação nagô, de nome Luiza Mahin, pagã, que sempre recusou o batismo e a doutrina cristã. Minha mãe era baixa, magra, bonita, a cor de um preto retinto, sem lustro, os dentes eram alvíssimos, como a neve. Altiva, generosa, sofrida e vingativa. Era quitandeira e laboriosa. Luiza Mahin teve outro filho, lembrado em versos por Luiz Gama, cuja história é ignorada.

Na luta por liberdade, contou com várias mulheres: Zeferina, no quilombo de Urubu (na Bahia), comandou, em 1826, um levante contra a capital baiana, onde manejava com muita habilidade o arco e flecha; Zacimba Gaba, Felicidade, Ludovina, Germana e Tereza participaram da Revolta das Armações de Pesca em Tapoã, na Bahia (RUFINO, 1985).

Furtado (2003) retrata Chica da Silva distinguindo-a do estereótipo veiculado pela mídia televisiva e apresentando-a como uma figura de resistência. Chica da Silva, filha de mãe negra, forra, ascendeu socialmente acumulando bens e riquezas, transitou entre diversas irmandades, cuidou da sua descendência garantindo para eles um lugar numa sociedade branca excludente. Para a autora, foi a forma que ela encontrou para controlar e manter sua vida que era negada pela sua condição feminina e negra.

Uma forma de resistência muito criticada foi o aborto. Para Giacomini (1988), diante dos maus tratos que sofria mãe e criança, não seria inconveniente ou sem cabimento identificar a prática do aborto como uma forma de resistência da escrava. "... a escrava mata o filho, antes de nascer... para poupar à sorte miseranda que o aguarda; mata o escravo querido, para lhe dar a única alforria a que pode aspirar" (DIÁRIO DO RIO DE JANEIRO, 17 jul. 1871, apud GIACOMINI, 1988).

A religião afro-brasileira também é apresentada como um caminho de resistência. Alguns historiadores defendem a tese de que a união dos escravos (as) se dava por meio dela, uma vez que os mesmos foram agrupados em diferentes etnias. Apesar da pressão policial que reprimia com violência a prática aos cultos afro-brasileiros a resistência firme das Mães de Santo (lalorixás) transformou a religião afro-brasileira como sendo um espaço de resistência negra (RUFINO, 1985).

Grupos resistiram com muita força e criatividade a exemplo das quitandeiras e as vendedoras ambulantes que tinham um grande prestígio na comunidade, sendo valorizadas 
por seu conhecimento e experiência. Extrapolavam muitas vezes as suas funções de vendedoras e desempenhavam outras, como de benzedeiras e espiãs. As autoridades coloniais e depois imperiais passaram a limitar a ação dessas mulheres, pois elas mantinham contato com os escravos fugidos. Dessa forma, facilmente se tornavam intermediárias dos quilombos, vendendo os produtos que eles produziam e comprando tudo quanto os quilombolas necessitavam para a sobrevivência. Quando o movimento abolicionista chegou às ruas, quitandeiras e vendedoras como Adelina Charuteira, de São Luiz do Maranhão mantinha informados os abolicionistas sobre os planos escravocratas, ajudando, desta forma, a fuga de escravos (MOTT, 1991).

As formas de resistência aqui são ilimitadas, passam pela fuga, luta armada, organização de quilombos, cultura, religião. As marcas da resistência encontradas no cotidiano das mulheres negras são heranças diretas da força e da coragem das quitandeiras, vendedoras, guerreiras, benzedeiras e lalorixás.

Em 13 de maio de 1888, a Princesa Isabel, do reino de Portugal, em lugar do imperador, sanciona lei aprovada na Câmara dos Deputados do Império, que aboliu a escravatura no Brasil. O fato de ela ter sancionado a lei foi explorado pela imprensa da época e pelos grupos dominantes de forma ideológica, como um ato de bondade.

Essa ideia pode ser desmistificada de várias maneiras: primeiro, considerando a proporção de escravizados que se beneficia, segundo Bento (1998), apenas 20\% da população negra do período. Segundo, a relutância do império em acabar com o escravismo em propiciar qualquer benefício aos ex-escravizados, como propunha, por exemplo, Luiz Gama, indenizações, doação de terras e instrução.

Entende-se, portanto, que a assinatura da Lei Áurea (Lei n ${ }^{3}$ 353) apenas reconheceu o que já era notório, pois além das fugas e rebeliões, existia a pressão internacional (Inglaterra) para que se criasse um mercado consumidor dos produtos europeus e isto não tornava o regime escravocrata rentável e viável. A assinatura da Lei Aurea é resultado das lutas, da resistência da população negra.

No meio urbano, no período pós-abolição, são as mulheres negras que assumem a responsabilidade de sustento de suas famílias, pois diferente dos homens, conseguiam empregos como: vendedoras nos mercados, serviços domésticos de cozinheira, copeira, lavadeira, babás e amas de leite. 
As mulheres sempre estiveram em movimento ora por sobrevivência, ora por inserção social e política e em todo tempo contra o racismo e suas expressões perversas. É no contexto de luta e organização que é creditada às mulheres negras sua participação na luta e aprovação da Lei Caó (Lei no 7.716/1989), que torna o racismo inafiançável e imprescritível.

Através dessas diversas formas de organização, os negros e especificamente, as mulheres negras têm conseguido resistir e sobreviver à situação de pobreza a que foram submetidas no pós-abolição e que tem sido reproduzida até os dias atuais.

\section{O lugar que as mulheres negras ocupam dentro do debate feminista e de gênero}

Uma das formas de exercer autonomia é possuir um discurso sobre si mesmo. Discurso que se faz muito mais significativo quanto mais fundamentado no conhecimento concreto da realidade (Neusa Santos).

A história do movimento feminista, de acordo com Toledo (2001), pode ser compreendida a partir de três grandes ondas. A primeira se situa no final do século XIX denominado de movimento sufragista (luta por direito ao voto feminino) e por direitos democráticos (direito ao divórcio, educação completa, trabalho etc.). A segunda foi no final dos anos 60, a luta por liberação sexual; e a terceira, no final dos anos 70, uma luta de caráter sindical, protagonizada pela mulher trabalhadora, na América Latina.

O movimento negro é uma organização política que cumpre o papel de explicitar a contradição nos cenários social, político e econômico (CUNHA, 1992, apud SOUSA, 1997).

Entende-se que, ao analisar os dois movimentos, em destaque o movimento feminista teve muito mais atenção por parte dos estudiosos e essa postura se intensifica nos estudos sobre mulheres. Caldwell (2000), investigando a produção teórica do movimento feminista brasileiro, identifica a ausência da raça na maioria das pesquisas sobre a mulher brasileira.

A luta das mulheres negras contra o racismo e suas manifestações através do preconceito e da discriminação racial e contra as contradições presentes na relação entre os gêneros tem feito progressos notáveis no campo dos direitos sociais e humanos. Contudo, a realidade demanda uma ampliação desta luta, com capacidade de apreender na dinâmica social os antagonismos presentes e inerentes a ela. 
Segundo Carneiro (2001), é em meio a esta dinâmica que o processo de emancipação, de busca de igualdade de direitos das mulheres negras ganha força estabelecendo novos desafios.

Para Araújo (2001), são motivadas pelo desejo de transformação da sua realidade que as mulheres negras aderiram aos movimentos feministas. Ao longo de sua trajetória, o feminismo tanto criou novos valores nas relações sociais como também muitos mitos de origem, entre eles o que se traduzia no paradigma de que todas as mulheres eram iguais.

O feminismo promoveu uma perspectiva universalista num discurso voltado para uma irmandade entre as mulheres e desta forma, não deu ênfase às diferenças. É na década de 8o, diz Araújo (2001), que, no seio do movimento feminista, as mulheres negras começam a levar para as discussões as suas especificidades tremulando uma nova bandeira de que eram mulheres, mas eram negras, logo com especificidades da raça. Portanto, um feminismo que ignore as divisões raciais está gravemente aberto às críticas.

Esta postura ocasionou lutas internas no movimento feminista, pois segundo Lélia Gonzalez, as feministas brancas com orientação progressista e, aparentemente, de esquerda, negaram o significado da raça e seu impacto nas vidas de mulheres negras. Enquanto na superfície parecia que as mulheres brancas e negras poderiam se unir e lutar contra sua opressão comum enquanto mulheres, diferenças entre elas, em termos de experiências e lugares, tornaram-se fontes de conflito e divisão dentro do movimento.

O movimento feminista não acolhe as questões postas pelas mulheres negras motivando-as para uma ação política organizativa específica em decorrência da insuficiência com que são tratadas as suas especificidades dentro do movimento feminista. As mulheres têm esta mesma postura com o movimento negro, posto que, em um estão os desdobramentos de gênero e no outro, não são enfatizadas as questões raciais.

Isto vai culminar no que Carneiro (2001), evidencia como dupla militância, que se impõe às mulheres negras como forma de assegurar que as conquistas no campo racial não sejam inviabilizadas pelas persistências das desigualdades de gênero e para que as conquistas dos movimentos feministas não privilegiem apenas as mulheres brancas.

Desta forma, a luta de combate ao racismo empreendido pelas mulheres negras abrange também a busca por uma real inserção social nos movimentos existentes; passam a questionar as desigualdades existentes entre brancas e negras, se posicionam contrárias ao 
discurso machista, bem como, o discurso de caráter universalista de cidadania², que deveria contemplá-las, mas que não passava de um mito.

É neste contexto que surge o movimento feminista negro ${ }^{3}$. O movimento surge do questionamento, não apenas por não responder às demandas específicas das mulheres negras pelo movimento feminista, mas também do questionamento de como as narrativas históricas apresentam a luta e as conquistas das mulheres. No seu texto enegrecer $o$ feminismo Carneiro (2011) interpela a história das mulheres contadas numa ótica branca e indaga algumas bases do fundamento das desigualdades de gênero:

Quando falamos do mito da fragilidade feminina, que justificou historicamente a proteção paternalista dos homens sobre as mulheres, de que mulheres estamos falando? Nós, mulheres negras, fazemos parte de um contingente de mulheres, provavelmente majoritário, que nunca reconheceram em si mesmas esse mito, porque nunca fomos tratadas como frágeis. Fazemos parte de um contingente de mulheres que trabalharam durante séculos como escravas nas lavouras ou nas ruas, como vendedoras, quituteiras, prostitutas... Mulheres que não entenderam nada quando as feministas disseram que as mulheres deveriam ganhar as ruas e trabalhar! Fazemos parte de um contingente de mulheres com identidade de objeto. Ontem, a serviço de frágeis sinhazinhas e de senhores de engenho tarados (CARNEIRO, 2011, p. 4).

Neste sentido concorda-se com a autora acima citada de que a perspectiva feminista que é colocada para as mulheres negras tem que entender que o gênero é uma variável, não podendo ser separada de outras formas de opressão, pois numa sociedade como a brasileira o racismo tem que ser considerado como um eixo articulador, pois este determina a hierarquia de gênero.

As marcas das lutas das mulheres negras não podem deixar de ser vistas dentro de toda essa dinâmica social e histórica. É no bojo das relações de raça e classe, pois assim está organizada a sociedade capitalista, que se evidenciam as questões de gênero e é nesse contexto que elas são reforçadas e reproduzidas.

2 O princípio de igualdade que norteia o acesso à cidadania nunca se efetivou, uma vez que não é extensivo a todos.

3 O Feminismo Negro é um movimento social e um segmento protagonizado por mulheres negras, com o objetivo de promover e trazer visibilidade às suas pautas e reivindicar seus direitos. No Brasil, seu início se deu no final da década de 1970 . 
O conceito de gênero aparece no cenário brasileiro na década de 8o, é historicamente fruto do movimento feminista e permite entender as relações sociais, enquanto construção social através de distintos papeis que a sociedade atribui a diferentes categorias de sexo,

Para Saffioti (1987), a sociedade delimita com bastante precisão os campos em que pode operar a mulher, da mesma forma como escolhe os terrenos em que pode atuar 0 homem. Para Fischer e Marques (2001), a perspectiva de gênero pressupõe mudanças, desconstruções dessa realidade historicamente determinada, em que as imposições da sociedade recaem principalmente, para o elemento feminino desprivilegiando-a frente à sua capacidade de conceber filhos, cuidar da casa, dando a esta "competência" um caráter natural em detrimento da possibilidade de construções socioculturais.

A teoria histórica material dá sua contribuição com essa discussão desmistificando a naturalização da subordinação da mulher, situando sua origem num processo gerado nas e pelas relações sociais. Essa postura é crucial para fugir a enfoques essencialistas, nos quais as desigualdades entre homens e mulheres são vistas como naturais (ARAÚJO, 2001).

A luta das mulheres não se dá somente na superação dessas desigualdades geradas pela histórica hegemonia do sexo masculino, mas também impõe o combate a outras ideologias como o racismo. Para Carneiro (2001), há sempre uma dimensão racial na questão de gênero, e uma dimensão de gênero na problemática étnico-racial. Portanto, desprezar a variável racial na temática de gênero é deixar de aprofundar a compreensão de fatores culturais racistas e preconceituosos.

\section{As conquistas das mulheres negras}

A resistência das mulheres negras tem resultado em conquistas. São conquistas concretas, mas não isentas de dificuldades. Suas lutas para conquistar espaços de representação têm sido exitosas, mas não podemos ignorar que, para as alcançarem, seus esforços são profundamente fruto da resistência. Luta pela sobrevivência, por acesso à educação, saúde, mercado de trabalho, moradia digna, acesso ao ensino superior, para manter vivos seus filhos/as.

É notório que ainda há um longo caminho a ser trilhado, principalmente quando a conjuntura não garante os direitos já conquistados e impede que novos direitos sejam legitimados. A despeito de todas as adversidades, as mulheres negras têm chegado às 
universidades, têm realizado pesquisadas considerando as demandas do seu grupo racial e proposto teorias que têm denunciado e descontruído o racismo e discutindo os diversos temas que dão conta da totalidade da vida social de mulheres e homens negros; são chefes de família, tendo que ter criatividade para driblar aquilo que o Estado brasileiro tem negado, têm transformado suas dores em luta; têm conseguido conquistas legais.

Mas o que motiva, anima essas mulheres, considerando que estão inseridas em uma sociedade organizada de forma hierarquizada e que tem contribuído há séculos pela manutenção do racismo? De acordo com Carneiro (2011, p. 8), o que impulsiona essa luta é a crença

na possibilidade de construção de um modelo civilizatório humano, fraterno e solidário, tendo como base os valores expressos pela luta anti-racista, feminista e ecológica, assumidos pelas mulheres negras de todos os continentes, pertencentes que somos à mesma comunidade de destinos". Pela construção de uma sociedade multirracial e pluricultural, onde a diferença seja vivida como equivalência e não mais como inferioridade.

As mulheres negras defendem a diversidade e o respeito inerentes a ela. A luta incansável dessas mulheres tem despertado as mulheres negras jovens a construírem uma identidade sólida, cuja estrutura é a história vivida e narrada dessas mulheres que resistiram e resistem todos os dias. Mulheres que têm a ancestralidade como referência e que não se subordinam à história, mas foram e são capazes de instituir uma história com valores distintos daqueles que historicamente foi imposto.

Por fim, com relação às políticas públicas mais recentes, destaca-se a participação das mulheres negras na conquista da lei 10639/03, que versa sobre a obrigatoriedade do ensino da África e da cultura afrodescendente nos espaços educacionais, a regulamentação do trabalhador doméstico, uma vez que é significativo o número de mulheres inseridas nesse ofício. A história de conquistas de direitos e a luta para sua garantia e manutenção não pode hoje deixar de registrar a participação das mulheres negras. Muitas batalhas se apresentam, mas as mulheres negras saíram do silêncio imposto pela sociedade eurocêntrica, racista, classista, vêm superando os rótulos, categorizações e certamente caminharão na esperança de que, enquanto existir correntes que inibam nossos passos, haverá luta. 


\section{Considerações finais}

Após a trajetória percorrida ao longo desse trabalho é possível constatar que falamos de uma história obscurecida e que as mulheres negras tentam, se esforçam para trazer as claras, informando a partir de uma narrativa emancipatória, aquilo que a obscuridade nega.

A dinâmica social onde está inserida a mulher negra é movida pela ordem capitalista, o que faz com que a luta da maioria seja por direitos sociais e, muitas vezes, direitos básicos de sobrevivência, reivindicando junto aos poderes públicos a satisfação de demandas que decorrem das próprias exigências do capital, tal como ele se constitui atualmente.

A mulher negra sempre necessitou estar inserida na luta por melhores condições de existência e isto se dava através de diversas formas de organização, desde o período escravista, no pós-abolição e até os dias atuais, com organizações que nem sempre se acomodaram nos moldes formais, mas que sempre foram constantes.

Segundo Theodoro (2016, p. 103):

As mulheres negras são, EXISTEM, sem pedir licença, tendo plena consciência de tal fato, vivendo em condições de extrema penúria, mas mantendo uma feição própria, se estruturando como PESSOA que toma para si a responsabilidade de manter a unidade familiar, a coesão grupal e a preservação das tradições culturais e religiosas de seu grupo, em função de sua paixão pela vida, de sua capacidade de se indignar diante das injustiças e de seu sonho de mudar a realidade para um mundo pleno de luz, música, risos, felicidade.

Resistência tem sido o caminho de aprendizado, de fortalecimento e de criação da possibilidade do sonho.

\section{Referências}

ARAÚJO, Clara. Marxismo, feminismo e o enfoque de gênero. In: Crítica marxista. São Paulo, Boitempo, n. 11, 2000.

ARNT, Ricardo; BONALUME NETO, Ricardo. A cara de Zumbi. Revista Super Interessante. [S. I.], ano 9, n. 11, 1995.

BENTO, Maria Aparecida Silva. Cidadania em preto e branco. São Paulo: Ática, 1998.

BERGMANN, Michel. Nasce um povo. Rio de Janeiro: Vozes, 1964.

CALDWELL, Kia Lilly. Fronteiras da diferença: raça e mulher no Brasil. Estudos feministas. [S. I.], p. 91-108, 2000. 
CARNEIRO, Sueli. Enegrecer o feminismo: a situação da mulher negra na América Latina a partir de uma perspectiva de gênero. Geledés Instituto da Mulher Negra. Disponivel em:

$<$ https://www.geledes.org.br/enegrecer-o-feminismo-situacao-da-mulher-negra-na-america-latinapartir-de-uma-perspectiva-de-genero/> Acesso em: 15 abr. 2018.

CALDWELL, Kia Lilly. Gênero e raça. In: Estudos de gênero face aos dilemas da sociedade brasileira. São Paulo: 2001.

FISCHER, Izaura Rufino. MARQUES, Fernanda. Gênero e exclusão social. Recife: Fundação Joaquim Nabuco, 2001.

FREYRE, Gilberto. Casa grande e Senzala. 23. ed. Rio de Janeiro: Livraria José Olympio,1984.

GIACOMINI, Sônia Maria. Mulher escrava: uma introdução ao estudo da mulher negra no Brasil. Petrópolis: Vozes, 1988.

GONZALEZ, Lélia. A mulher negra na sociedade brasileira: uma abordagem político-econômico. In: LUZ, Madel. O lugar da mulher. Rio de Janeiro: Graal, 1982. p. 87-106.

WERNECK, Jurema. Nossos passos vêm de longe! Movimentos de mulheres negras e estratégias políticas contra o sexismo e o racismo. In: Revista da Associação Brasileira de Pesquisadores/as Negros/as (ABPN), [S.I.], v. 1, n. 1, p. 07-17, jun. 2010. ISSN 2177-2770. Disponível em:

<http://abpnrevista.org.br/revista/index.php/revistaabpn1/article/view/303>. Acesso em: 08 abr. 2018.

RUFINO, Alzira. Uma retrospectiva histórica. São Paulo: 1987.

SAFFIOTI, Heleieth. Posfácio: conceituando o gênero In: Mulher brasileira é assim. Brasília, DF: Rosa dos tempos: NIPAS; Rio de Janeiro: UNICEF, 1994.

SOUZA PESSOA, Cintia Lizandre Santos. Vestígios da Negação: Um olhar sobre as diversas contribuições da história da África para a afirmação da negritude da Mulher negra. Monografia. Recife, 2017.

SOUZA, Tereza Cristina Vital de. Com a palavra o Movimento Negro. Contestando o racismo e desmistificando a democracia racial. Recife: 1997.

THEODORO, Helena. Encrespando - Anais do I Seminário Internacional: Refletindo a Década Internacional dos Afrodescentendes (ONU, 2015-2024) / FLAUZINA, Ana; PIRES, Tula (Org.). Brasília: Brado Negro, 2016.

\section{Valdenice José Raimundo}

Doutora em Serviço Social pela UFPE. Leciona na Graduação e na Pós-graduação em Serviço Social da Universidade Católica de Pernambuco. É líder do Grupo de Estudos e Pesquisas em Raça, Gênero e Políticas Públicas/UNICAP. Ganhou o prêmio Mulheres Negras Contam Sua História. É Acadêmica da Academia Vitoriense de Letras, Artes e Ciências. Sócia do Instituto Histórico e Geográfico da Vitória de Santo Antão. Coordenadora do Núcleo de Estudos Afro-Brasileiros e Indígenas - UNICAP. Pesquisadora Associada do Instituto de Estudos da África - IEAF/UFPE. Tem experiência na área de 
ensino, pesquisa e extensão, com ênfase nos direitos sociais, juventude, gênero, movimentos sociais e questões étnico raciais. E-mail: valdenice@unicap.br 